\title{
Applications of anthropometry in torsoplastic surgery
}

\author{
Fabio Fantozzi
}

Received: 18 April 2013 / Accepted: 2 May 2013 / Published online: 30 May 2013

(C) The Author(s) 2013. This article is published with open access at Springerlink.com

\begin{abstract}
The study of anthropometry defines the beauty of the torso from a geometric perspective. Anthropometry therefore aids the plastic surgeon in planning the reshaping of the torso and also makes positioning of areolae and the umbilicus easier. When performing surgery on the breast, it is necessary to relate the breast to the torso as a whole, being anthropometry perfect for this process. When the anthropometric proportions are respected, the result is aesthetically optimal, and the perceived beauty of the body is enhanced. The study of anthropometry is widespread in the artistic field, and I have chosen the work of sculptor, Carlo Rochet, as the basis for my own use of anthropometry during plastic surgery. Level of Evidence: Level V, diagnostic study.
\end{abstract}

Keywords Anthropometry - Torso $\cdot$ Positioning of areola . Positioning of umbilicus · Plastic surgery · Aesthetic surgery · Torsoplasty $\cdot$ Torsoplastic

\section{Introduction}

The study of anthropometry defines the beauty of the torso from a geometric perspective. Anthropometry therefore aids the plastic surgeon in planning the reshaping of the torso.

For example, when performing surgery on the breast, it is necessary to relate the breast to the torso as a whole, through the application of anthropometry. When the anthropometric proportions are respected, the result is aesthetically optimal and the perceived beauty of the body is enhanced. This

F. Fantozzi $(\bowtie)$

ACEIP (European Surgical Association of Prof. Ivo Pitanguy

Alumni), Rome, Italy

e-mail: fa.fantozzi@tiscali.it anthropometric approach also makes positioning of areolae and the umbilicus very easy.

A rich source of anthropometric studies can be found in the art world. Artists are often involved in the portrayal of beauty and they have developed techniques for determining and describing such. This process goes at least as far back as Leonardo da Vinci.

As the basis for my own practise, I have found nineteenth century sculptor, Carlo Rochet's book, Le Leggi Naturali Delle Proporzioni ('The Natural Laws of Proportion') [1] an excellent source, and some of his illustrations, somewhat modified, are herein presented. In this article, I will focus specifically on the application of anthropometry when performing plastic surgery on the torso.

\section{Methods}

In order to apply the anthropometry of the torso, I have gone back to the anthropometric studies of the nineteenth century sculptor Carlo Rochet (Figs. 1, 3 and 4). The anthropometric underpinnings of beauty are well-known to artists, as they have to reproduce it in their works. I have been using Rochet's anthropometric studies as the starting point for all my plastic surgery procedures.

Carlo Rochet's scale (Fig. 1) divides the torso, the head, the upper limbs and the lower limbs into four equal sections, each representing the same proportions. When these anthropometric proportions are respected, we have an 'ideal' body contour (Fig. 1).

Clearly, as plastic surgeons, we cannot choose the dimensions of our patients as a sculptor like Rochet can. However, we should understand this objective geometrical analysis of beauty to help us improve, as far as 


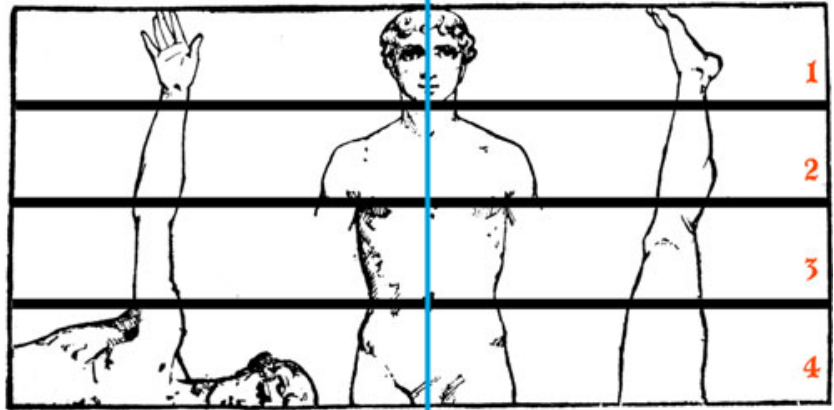

Fig. 1 Dividing the body into equal sections [1]. Figure 1 was adapted from images taken from an out-of-copyright book on anthropometry authored by sculptor Carlo Rochet [1] during the nineteenth century

possible, the body's contours. Turning now to the torso itself, the correct proportions are achieved by dividing the space between the lower jaw and the inner thigh radix into thirds (Fig. 2):

- First, we measure the position of the lower jaw and the inner thigh radix.

- Finally, we divide the space into three equal sections.

Note: The lower jaw is measured when the patient's face is looking directly ahead (i.e. at $90^{\circ}$ ).

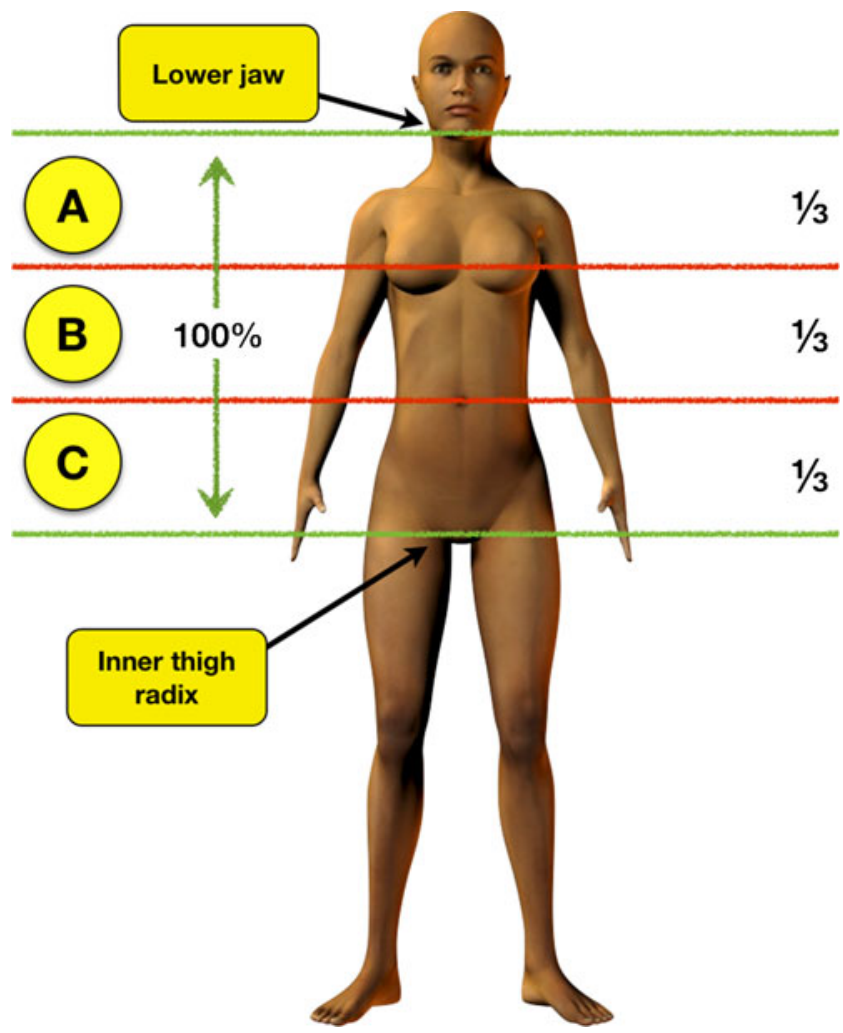

Fig. 2 Torso proportions. The red lines located at the one- and twothird levels identify the correct location of the nipples and umbilicus, respectively (C2013, Fabio Fantozzi, M.D. All rights reserved)
Positioning the areolae

When performing plastic surgery on the breast, it is necessary to consider the torso as a whole, using anthropometry (Fig. 3). The proportions are considered correct when the height of the head is equal to the distance between:

- The lower jaw and the nipples (section A)

- and between the nipples and the umbilicus (section B)

By applying this anthropometric technique, the remodelled breasts will have the correct anthropometric proportions, enhancing the beauty of the patient.

Positioning the umbilicus

The umbilicus is positioned using a similar technique to the areolae (Fig. 4). The torso is divided into four equal sections by transverse lines:

1. Top of the head to the chin

2. Chin to nipples

3. Nipples to umbilicus

4. Umbilicus to inner thigh radix

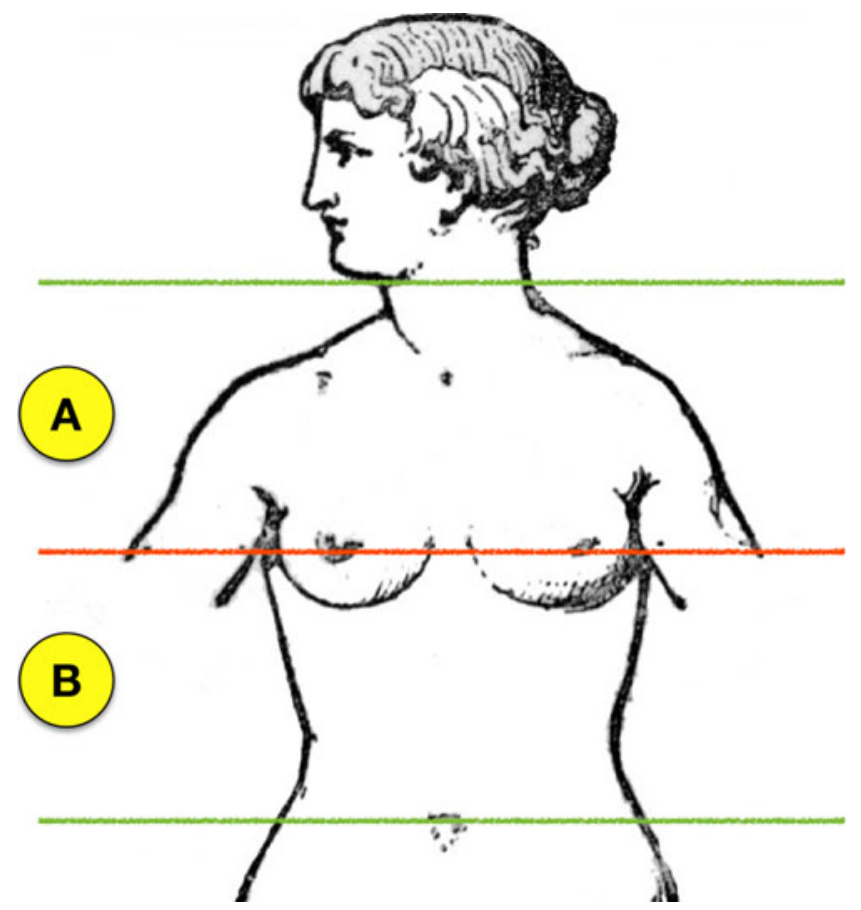

Fig. 3 Sections A and B are the same height. Only when these distances are observed can we achieve the correct proportions of the breast relative to the torso [1]. Figure 3 was adapted from images taken from an out-of-copyright book on anthropometry authored by sculptor Carlo Rochet [1] during the nineteenth century 


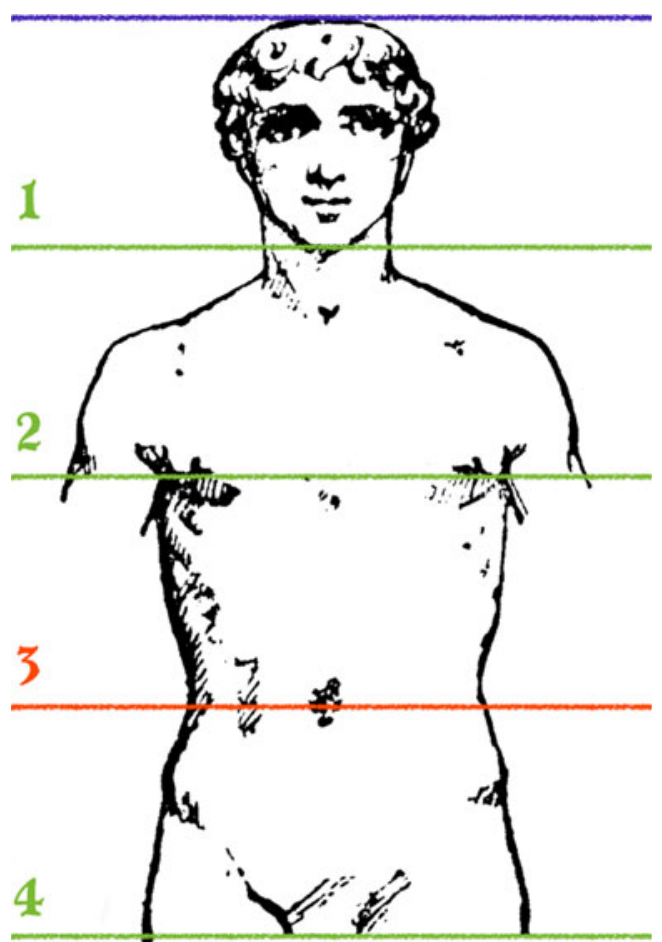

Fig. 4 Positioning the umbilicus. The torso is divided into four equal sections, providing the information needed to determine the correct positioning of the umbilicus [1]. Figure 4 was adapted from images taken from an out-of-copyright book on anthropometry authored by sculptor Carlo Rochet [1] during the nineteenth century

With this information, we can now look at how to apply the anthropometric procedures in practise.

Measuring the proportions

\section{Step 1}

In Fig. 5, the patient is being measured using a modified measuring stick.

- The customisation of the measuring stick enables easier use of the measuring stick for anthropometric purposes.

- The reader bar must be at $90^{\circ}$.

- The angle of the patient's chin must be at $90^{\circ}$ with respect to the neck.

In this example, the height recorded is $154 \mathrm{~cm}$.

\section{Step 2}

We continue using the customised measuring stick (Fig. 6), with its $90^{\circ}$ angle indicator.

- We measure the height of the umbilicus.

- In this example, the height recorded is $106 \mathrm{~cm}$

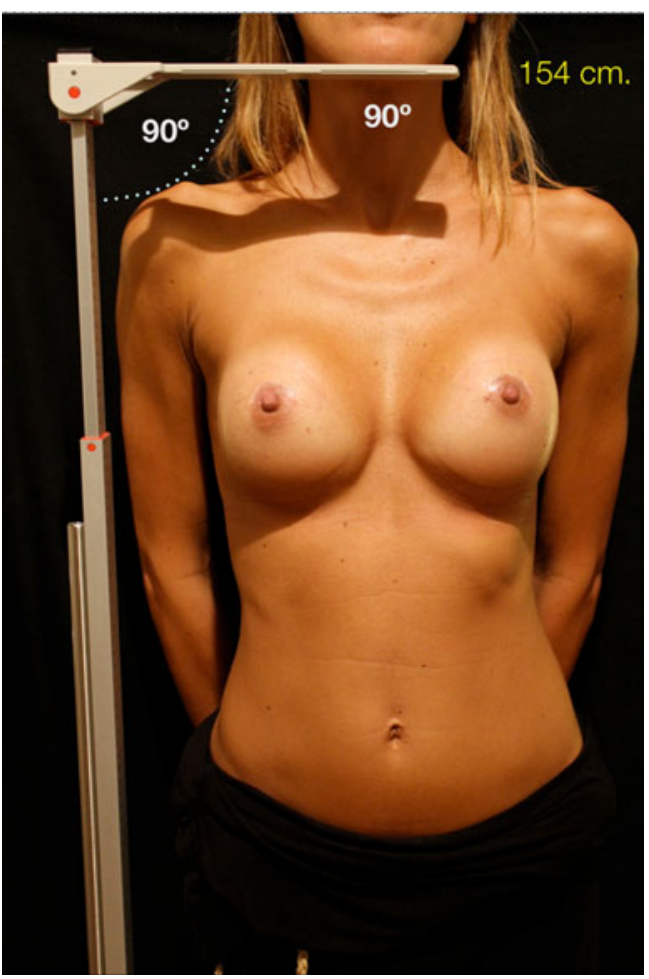

Fig. 5 Measuring the height of the patient's chin (C2013, Fabio Fantozzi, M.D. All rights reserved)

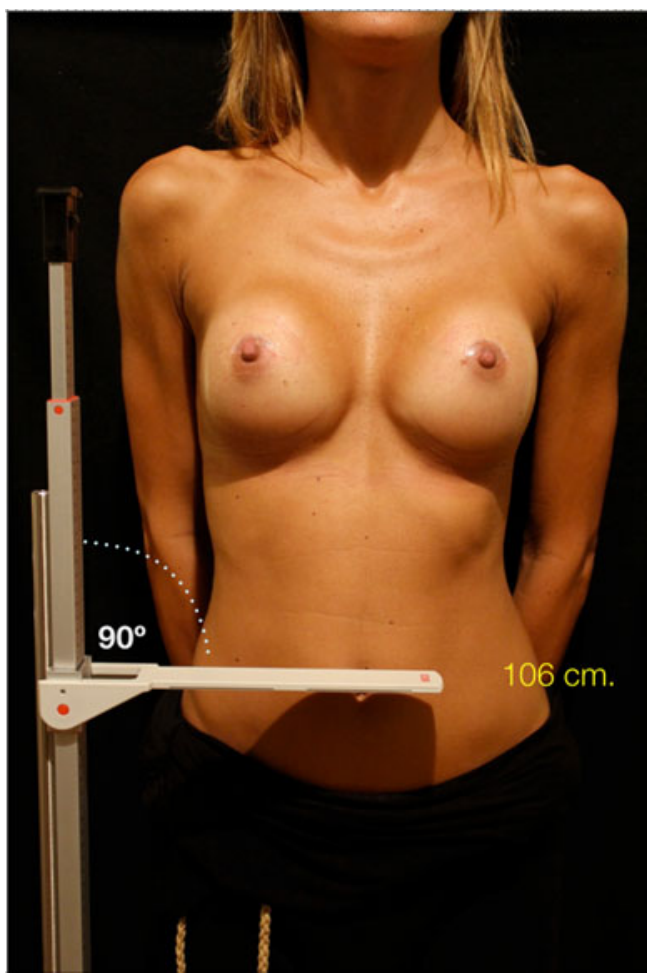

Fig. 6 Measuring the height of the patient's umbilicus (C2013, Fabio Fantozzi, M.D. All rights reserved) 


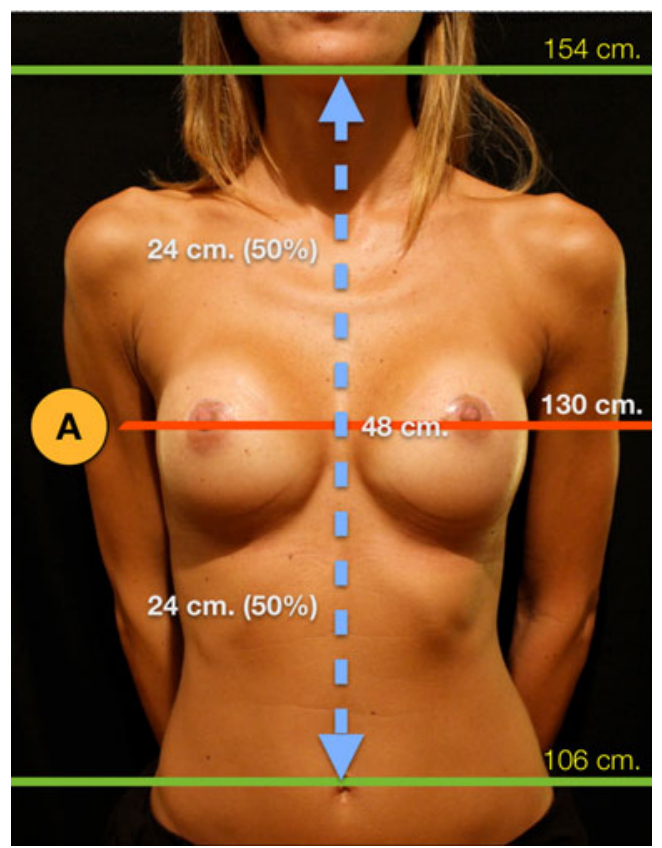

Fig. 7 Calculating the midpoint. Note how $A$ passes is in line with the patient's areolae (C2013, Fabio Fantozzi, M.D. All rights reserved)

\section{Step 3}

With the measurements completed, we can now calculate the correct positioning of the mid-point (Fig. 7). This gives us the correct positioning of the areolae.

- The height of the chin is $154 \mathrm{~cm}$.

- The umbilical height is $106 \mathrm{~cm}$.

- The distance between the chin and the umbilicus is $48 \mathrm{~cm}$.

- The distance to the mid-point from each line is therefore $24 \mathrm{~cm}$. Line ' $A$ ' in Fig. 7 shows this. In this example, the mid-point is at a height of $130 \mathrm{~cm}$.

\section{Case presentations}

Case 1: Breast enhancement

In this case study (Fig. 8), the patient evaluation was as follows:

- Section A was $60 \%$ against section B's $40 \%$.

- The patient requested a breast augmentation.

- To obtain an aesthetically pleasing surgical result, it was necessary to raise the areola by at least $2.5 \mathrm{~cm}$, with respect to its original position.

The results are shown in Fig. 8. In this case, the reshaping involved lifting the areola using a semi-circular skin resection and insertion of round implants $\left(280 \mathrm{~cm}^{3}\right)$. After surgery, section $\mathrm{A}$ is equal to section $\mathrm{B}$.

Case 2: Breast reduction (with mastopexy)

- In this example (Fig. 9), section A is $75 \%$ against section B's $25 \%$.

- The patient has requested a breast reduction with mastopexy.

- To obtain an aesthetically pleasing surgical result, it is necessary to raise the areola by about $8 \mathrm{~cm}$, with respect to its original position.

The result is shown in Fig. 9. In this case study, the surgery involved breast reduction (600 $\mathrm{g}$ right breast, $700 \mathrm{~g}$ left breast.) After surgery, section A is equal to section B.

\section{Case 3: Abdominal reconstruction}

The patient requested an abdominal reconstruction due to complex peritonitis causing multiple abdominal hernias (Fig. 10).

- We start at the inner thigh radix, at $98 \mathrm{~cm}$.
Fig. 8 Case study 1; before surgery and 6 months after surgery (C2013, Fabio Fantozzi, M.D. All rights reserved)

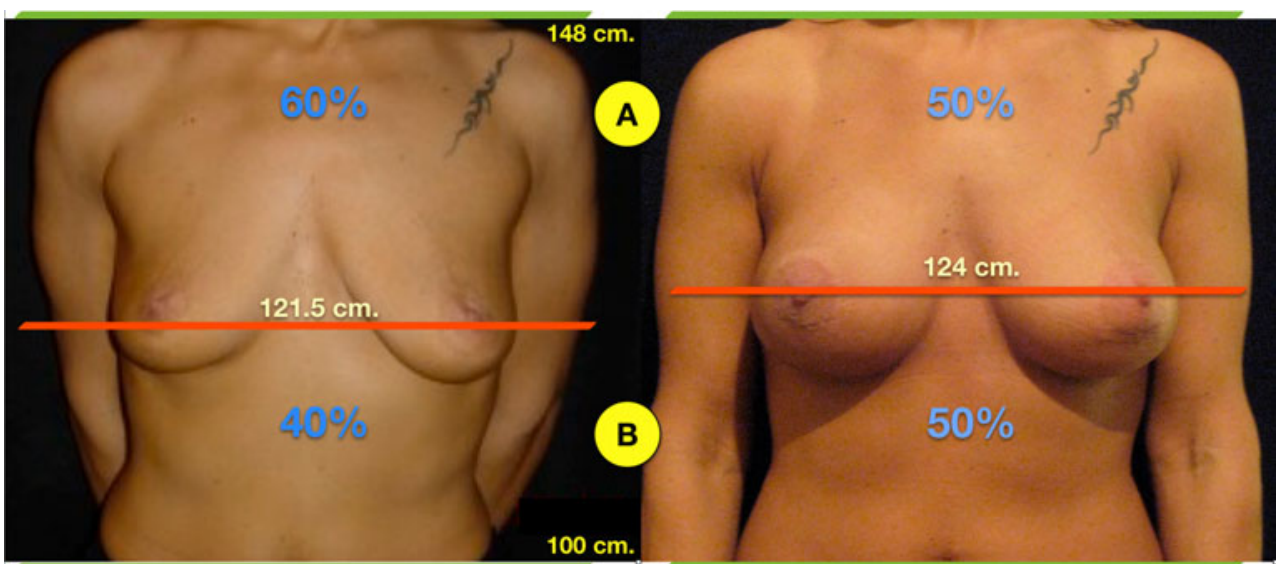


Fig. 9 Case study 2; before surgery and 10 months after surgery (C2013, Fabio Fantozzi, M.D. All rights reserved)

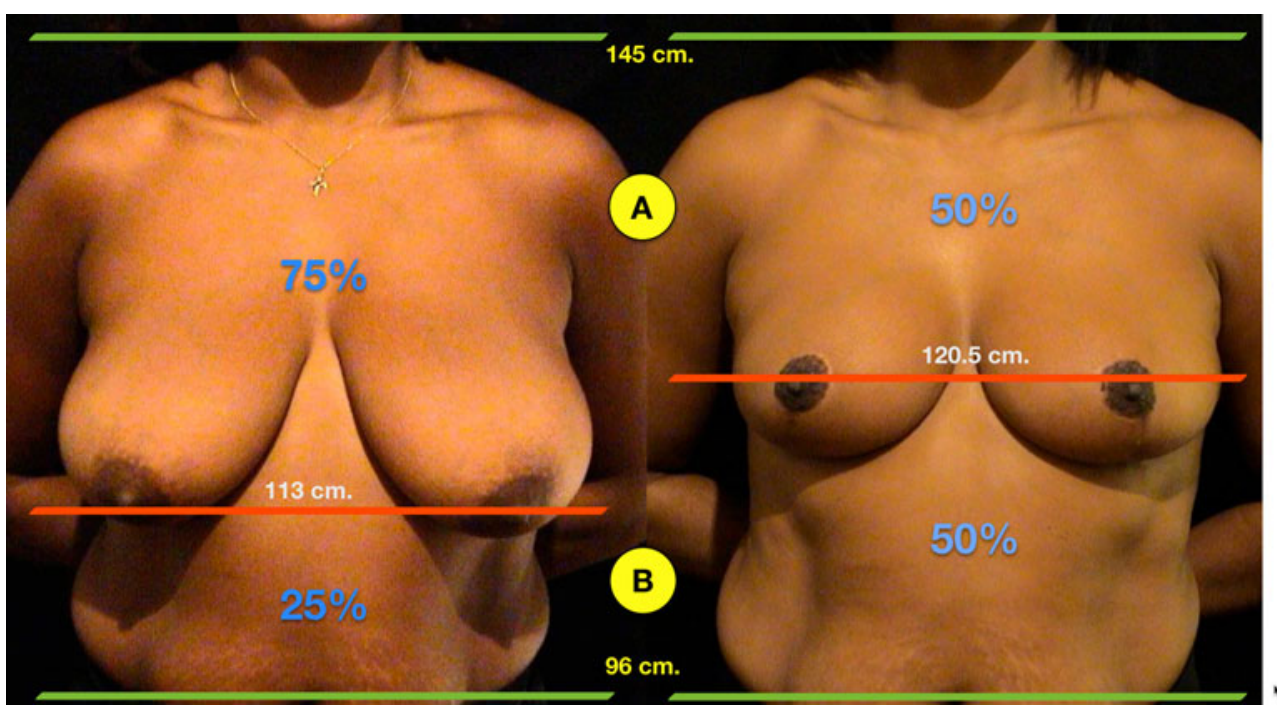

- Next, we measure the height of the chin. In this example, it is $152 \mathrm{~cm}$.

- To obtain an aesthetically pleasing surgical result, we divide the space between these two heights into three equal areas of $18 \mathrm{~cm}$ each.

- The umbilicus should be raised to $116 \mathrm{~cm}$ (to the $1 / 3$ position) measured from the inner thigh radix.

The result of the surgery is shown in Fig. 10. After surgery, the umbilicus has been lifted to $116 \mathrm{~cm}$.

This complex operation was a treatment of a multiple hernia involving reconstruction of the peritoneum using a polypropylene mesh, followed by abdominoplasty. After this treatment, the umbilicus met the correct anthropometric proportions.
Case 4: Abdominoplasty and mammoplasty

The patient requested both mammoplasty and abdominoplasty procedures (Figs. 11 and 12).

- We start at the inner thigh radix at $88 \mathrm{~cm}$.

- Next, we measure the height of the chin. In this example, it is $139 \mathrm{~cm}$.

- To obtain an aesthetically pleasing surgical result, we divide the space between these two heights into three equal areas of $17 \mathrm{~cm}$ each.

- The umbilicus should be raised to $105 \mathrm{~cm}$ - the $1 / 3$ position, measured from the inner thigh radix.

- The areolae should also be raised to $122 \mathrm{~cm}$.
Fig. 10 Case study 3; before surgery and 8 months after surgery (C2013, Fabio Fantozzi, M.D. All rights reserved)

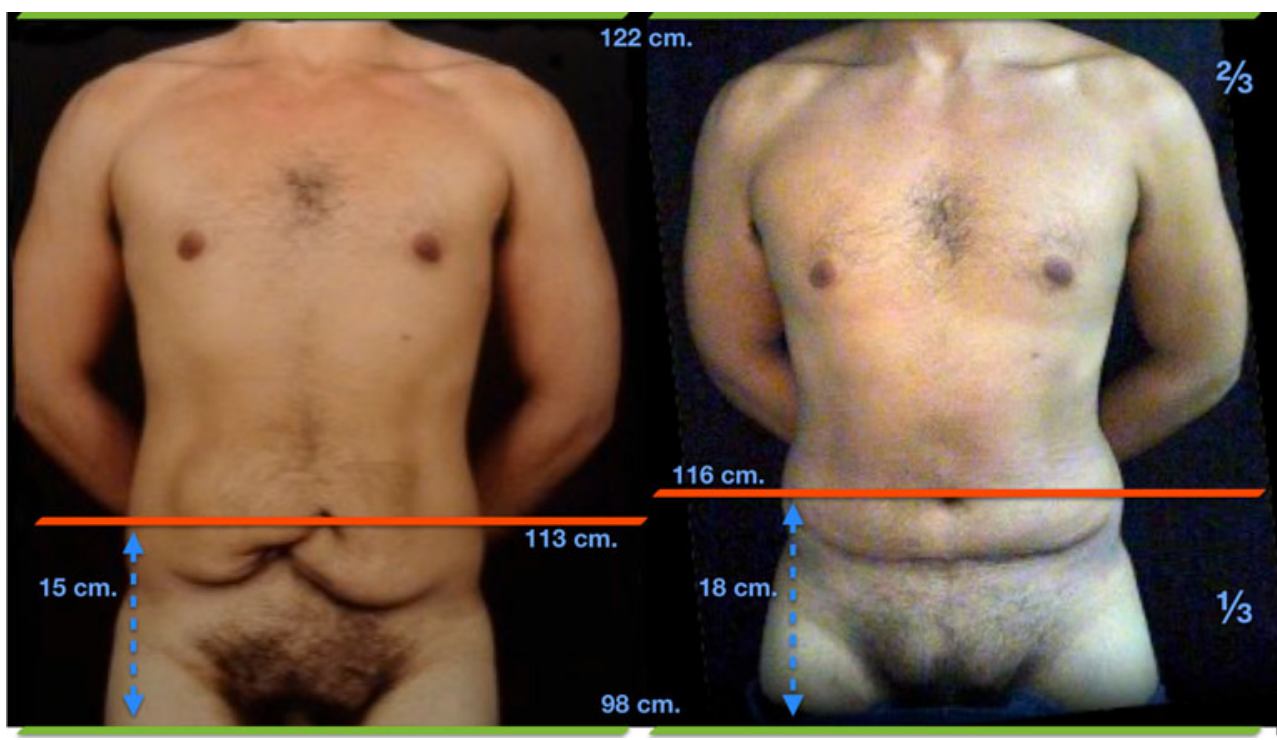


Fig. 11 Case study 4; front view, before surgery and 8 months after surgery (C)2013, Fabio Fantozzi, M.D. All rights reserved)

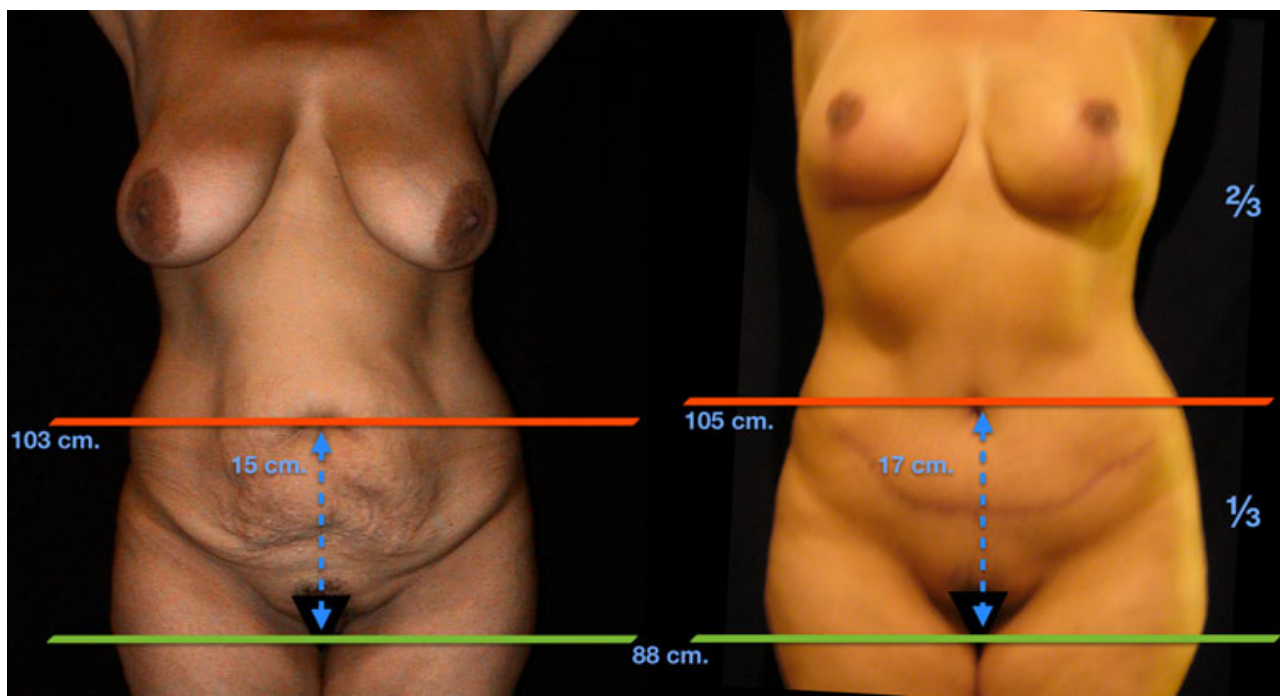

The results can be seen in Figs. 11 (front view) and 12 (side view). In this case study, we are interested in the abdominoplasty results. The umbilicus has been lifted to $105 \mathrm{~cm}$ from its original height of $103 \mathrm{~cm}$. As you can see, the rule of thirds has been successfully applied.

\section{Discussion}

Artists and sculptors have been applying the principles of anthropometry for centuries, from the time of da Vinci to the modern day. Familiarity with the principles of anthropometry and its relationship with beauty mean we can use anthropometry as an objective tool during our procedures.

For my own practise, I have been relying on the work of the sculptor Carlo Rochet, whose book on anthropometry, The Natural Laws of Proportion [1], was published in Italy in the late 1800 s and is now in the public domain. This book provided some of the images used in this article and is the basis of my application of anthropometry to my aesthetic and plastic surgery procedures.

The modified measuring stick, a very simple tool, allows us to measure the patient and calculate the
Fig. 12 Case study 4; side view, before surgery and

8 months after surgery (C2013, Fabio Fantozzi, M.D. All rights reserved)

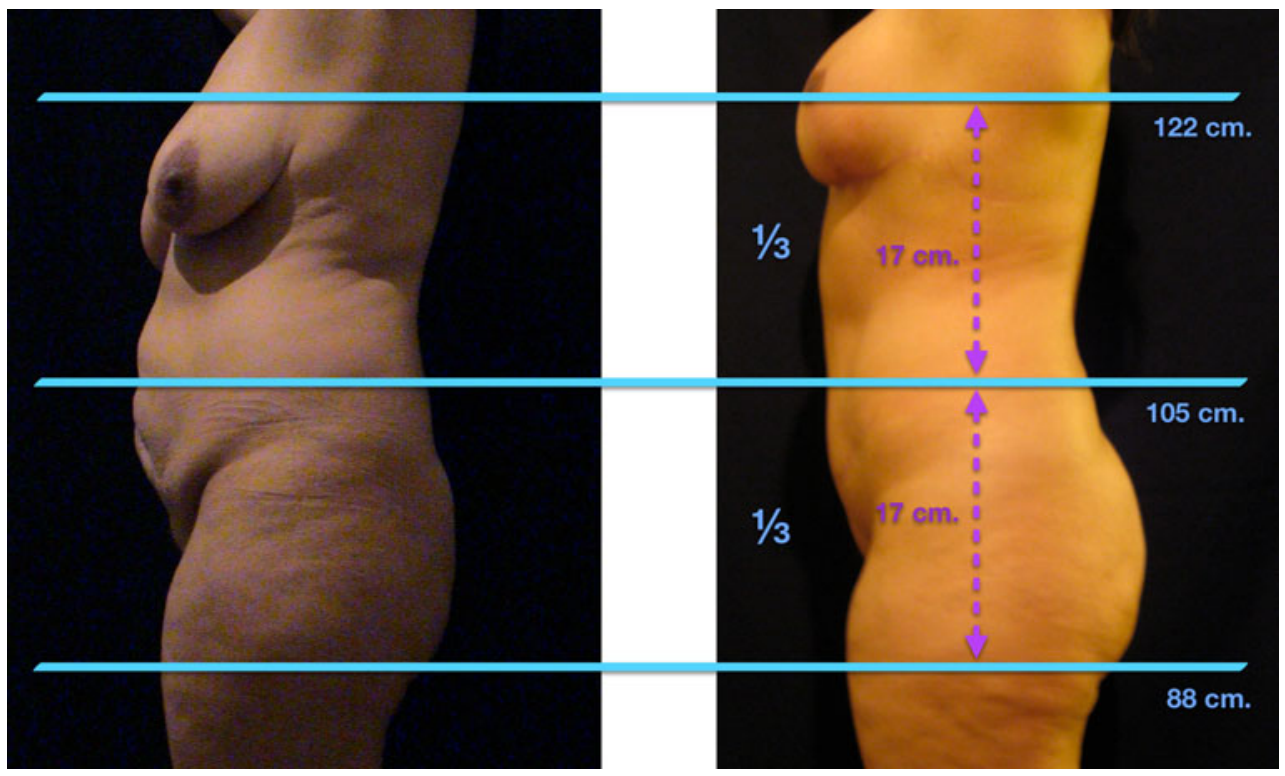


correct positioning of the areolae and umbilicus so as to maintain the correct anthropometric proportions. When remodelling the torso, we should apply anthropometry to ensure correct positioning of the areola and the umbilicus. The breast and umbilicus are part of the torso and have an anthropometric relationship: the rule of thirds. Each time this anthropometric rule is met, we obtain an aesthetically optimal result.

Body proportions can vary greatly, so this anthropometric approach should be seen as a guideline. It is not applicable to all cases, such as unusually long or short torsos. However, in most cases, these rules can help reduce the effects of flawed anthropometric proportions.

Perhaps the most important aspect is that the application of anthropometric principles offers a strongly objective method for determining the correct proportions for our patients. While superficial concepts of beauty may have changed, the underlying anthropometric proportions have been very stable over time. Statues created a thousand years ago show the same anthropometric proportions applied back then just as they do today.

A search on PubMed for articles relating to the use of anthropometry in plastic surgery reveals this specific application of anthropometry has not been the subject of any research. Most of the studies on the application of anthropometry in plastic surgery found in the medical literature dealt with the craniofacial and aesthetic facial surgery field [2-7].

I was surprised to discover that none of the papers found considered applying traditional anthropometric techniques and analyses from the art world, where similar research into optimal proportions has already been performed for the benefit of artists and sculptors.

Of the cases returned in our searches, RodriguezFeliz et al. [8], Pallua et al. [9] and Rohrich et al. [10] are specifically about the positioning of the umbilicus, with each paper applying a statistical analysis approach. Avşar et al. [11] created a statistical dataset derived from measurements of Turkish patients to guide repositioning of applications of anthropometry to the torso, including the areolae and umbilicus, with the dataset being inevitably biased towards typical Turkish body morphologies.

The evidence suggests that, although my approach relies on work already done in another field, my application of said research to the field of aesthetic and plastic surgery (with a particular focus on the torso) is indeed novel.
The existing literature relating to the anthropometry of the torso and its applications in plastic and aesthetic surgery generally ignores the existing research performed by artists and sculptors over the centuries. Of the few papers that look at anthropometry directly, many appear to be duplicating statistical research methods already in use by artists like Carlo Rochet back in the nineteenth century.

Some of the existing research looks at applying new measuring techniques, such as laser scanning of the face [5], a variant of which may be useful in measuring the torso too. Comparison of different techniques [6] is also of interest, but like most of the literature found [2-7], most researchers are focused on craniofacial applications, rather than the torso, which is the subject of this article.

The lack of research into applying knowledge gained in the field of art is surprising and it leads me to believe my approach is therefore new to the field of aesthetic and plastic surgery.

\section{Conflict of interest None}

Open Access This article is distributed under the terms of the Creative Commons Attribution License which permits any use, distribution, and reproduction in any medium, provided the original author(s) and the source are credited.

\section{References}

1. Rochet C (1887) Il Prototipo Umano Che Determina Le Leggi Naturali Delle Proporzioni In Ambedue I Sessi. Rome, Corso, 146: Modes \& Mendel, Librai-Editori (public domain). pp 2632

2. Christofides EA, Steinmann ME (2010) A novel anthropometric chart for craniofacial surgery. J Craniofac Surg 21(2):352357

3. Dong Y, Zhao Y, Bai S, Wu G, Wang B (2010) Three-dimensional anthropometric analysis of the Chinese nose. J Plast Reconstr Aesthet Surg 16(11):1832-1839

4. Arslan SG, Genç C, Odabaș B, Kama JD (2008) Comparison of facial proportions and anthropometric norms among Turkish young adults with different face types. Aesthetic Plast Surg 32(2):234-242

5. O'Grady KF, Antonyshyn OM (1999) Facial asymmetry: threedimensional analysis using laser surface scanning. Plast Reconstr Surg 104(4):928-937

6. Farkas LG, Tompson B, Phillips JH, Katic MJ, Cornfoot ML (1999) Comparison of anthropometric and cephalometric measurements of the adult face. J Craniofac Surg 10(1):18-25, discussion 26

7. Furnas DW (1987) Anthropometric landmarks for precision planning in rhytidectomy. Clin Plast Surg 14(4):639661 
8. Rodriguez-Feliz JR, Makhijani S, Przybyla A, Hill D, Chao J (2012) Intraoperative assessment of the umbilicopubic distance: a reliable anatomic landmark for transposition of the umbilicus. Aesthetic Plast Surg 36(3):8-17

9. Pallua N, Markowicz MP, Grosse F, Walter S (2010) Aesthetically pleasant umbilicoplasty. Ann Plast Surg 64(6):722-725
10. Rohrich RJ, Sorokin ES, Brown SA, Gibby DL (2003) Is the umbilicus truly midline? Clinical and medicolegal implications. Plast Reconstr Surg 112(1):259-263, discussion 264-5

11. Avşar DK, Aygit AC, Benlier E, Top H, Taşkinalp O (2010) Anthropometric breast measurement: a study of 385 Turkish female students. Aesthet Surg J 30(1):44-50 